\title{
Letrônica
}

\section{Locuções graduadoras coloquiais}

Coloquial degree expressions

Doutor e Mestre em Linguística pela Universidade Federal de Santa Catarina. Licenciado em Letras Português/lnglês pela Faculdade Estadual de

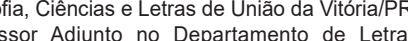
Pressor Adunto no Departamento de Letras Clássicas e Vernáculas do Instituto de Letras da (ii) htsp (1) http://orcid.org/0000-0002-4499-3820

\section{Recebido em: 3/10/2018} Aprovado em: 1/3/2019

\section{Endereço para correspondência:} Instituto de Letras Universidade Federal do Rio Grande do Sul Av. Bento Gonçalves, 9500 - Agronon
R

\section{RESUMO}

0 artigo discute os aspectos semânticos das locuções graduadoras encabeçadas por pra (pra caramba, pra chuchu e similares) e por $a$ (à beça, às pampas, a rodo e similares) e mostra que elas têm as mesmas interpretações de "muito", satisfazendo os critérios propostos por Guimarães (2007) para a identificação de um intensificador. Mostramos também que a discussão gramatical tradicional centrada na palavra impediu que se percebesse que o papel dos graduadores transcende a modificação adjetival/adverbial. Por fim, em relação ao significado das expressões, assumimos que a preposição denota uma relação entre um predicado e um lugar na escala relevante, sendo o nome complemento da preposição esse lugar na escala. Palavras-chave: Semântica. Modificação. Locuções Graduadoras.

\section{ABSTRACT}

The paper discusses some semantic aspects of degree expressions headed by pra 'to' (pra caramba, pra chuchu 'muito' and the like) and by $a$ 'to' (à beça, às pampas, a rodo 'muito' and the like) and shows that the expressions have the same readings as "muito" 'many/much/very', fulfilling the criteria proposed by Guimarães (2007) for the identification of an intensifier. We also show that the grammatical discussion focused on words prevented the consideration of the role of degree expressions beyond the adjectival/adverbial modification. At last, we assume that the preposition denotes a relation between a predicate and a place in the relevant scale, and the noun complement of the preposition is the place on the scale.

Keywords: Semantics. Modification. Degree Expressions. 


\section{Introdução}

\ eu objetivo principal é discutir as propriedades semânticas e sintáticas 1 de dois conjuntos de expressões. O primeiro é encabeçado pela preposição para, mais propriamente "pra”, nas locuções "pra burro", "pra cachorro", "pra caraca" etc.; e o segundo envolve as locuções encabeçadas por "a”, como "à beça”, "às pampas", “a rodo” etc. Em (1-2) vemos os exemplos típicos:

(1) a. Tenho sangrado demais, tenho chorado pra cachorro/ano passado eu morri, mas esse ano eu não morro (Belchior, Sujeito de sorte) ${ }^{1}$.

b. Pediu muita cadeira a requebrar/muita boca com dente pra caramba (Chico Buarque, Dias Gomes, Francis Hime, $O$ rei de ramos) ${ }^{2}$.

c. O samba de Maria Luiza é bonito pra chuchu (Tom Jobim, Samba de Maria Luiza $)^{3}$.

(2) a. Após a partida dos hóspedes, Paulo Bento riu a rodo e o negro acompanhante bobeou-se de alegria. (Caio Fernando Abreu, Onde andará Dulce Veiga?, 1990, CD) ${ }^{4}$.

b. - Que ele está cheio de gás, está, mas só agora é que ele acordou, e 13 anos já se passaram. Treze anos é coisa à beça. (Antônio Callado, $A$ madona de cedro, 1957, CD)

c. - Ora, lá no internato. Era cega, mas gostosa às pampas. (José Pixote Louzeiro, Infância dos mortos, 1977, CD)

Nesses exemplos, as expressões modificam categorias semânticas e sintáticas diferentes. Verbos de atividade em (1a) e (2a), com uma

1 Trecho transcrito de BELCHIOR. Sujeito de Sorte. São Paulo: Universal Music, 1976. Disponível em:

https://open.spotify.com/track/0ZhNovlwgZMvO05pEnsR02. Acesso em: 10 maio 2019.
2 Trecho transcrito de FRANCIS HIME. O rei dos ramos. São Paulo: Som Livre, 1980. LP (2min44s).

3 Trecho transcrito de TOM JOBIM. Samba de Maria Luiza. São Paulo: Sony Music, 1994. Disponível em:

https://open.spotify.com/track/1fJtRd9jU1b1tqr3LuBoFP. Acesso em: 10 maio 2019. interpretação de intensidade e uma leitura de duração temporal; Substantivos em (1b) e (2b), e o sintagma nominal se refere a uma grande quantidade de coisas e de dentes, respectivamente; por fim, adjetivos em (1b) e (2b), com interpretação de intensificação. Pela distribuição e interpretação, concluímos que essas locuções são intensificadores típicos. Mas aqui já enfrentamos o primeiro desafio: como caracterizar formalmente, em uma abordagem referencial do significado, a operação de “intensificação”? É a mesma operação semântica na modificação nominal, verbal e adjetival?

Intensificadores, ou graduadores, são expressões (um morfema, um item lexical, uma locução ou uma construção sintática) que modificam predicados que denotam propriedades graduais (KENNEDY, 1997). Essa caracterização soa circular: um graduador é um modificador de predicado gradual, e um predicado gradual é um predicado que pode ser modificado por um graduador.

Definições à parte, "gradação" e "intensificação" são noções empregadas para se referir a operações gramaticais de modificação que a tradição gramatical e a linguística contemporânea englobam na comparação canônica, nos advérbios de intensidade e no superlativo. Embora a modificação de substantivos por sufixos aumentativos e diminutivos tenha sido classificada também como "grau" pela nossa tradição gramatical, é claro que o fenômeno é diferente morfológica e semanticamente 5 .

Assim, a modificação gradual será entendida aqui como um processo semântico de modificação de predicados que denotam domínios organizados (ou não singulares). Marques (2004, p. 1 [grifos do autor]) esclarece que predicados escalares denotam “[...] uma propriedade escalar, isto é, uma propriedade mensurável em um conjunto de pontos ordenados segundo

5 Cf. GUIMARÃES, 2007, cap. 1; ou SILVA, 2015; para discussão. 
uma determinada dimensão, ou seja, uma escala". Portanto, a operação de modificação gradual pode ser definida mais precisamente como uma operação semântica que situa indivíduos em uma escala abstrata, escala esta denotada pela expressão que é modificada.

Isso quer dizer que adjetivos e advérbios graduais são predicados que denotam domínios que organizam os seus membros em função do grau que exibem da propriedade que o predicado denota. Por exemplo, "alto/ baixo" ordenam os indivíduos em função do grau que exibem de altura, e a diferença entre os polos é que "alto" ordena do mais baixo para o mais alto, e "baixo" do mais alto para o mais baixo (KENNEDY, 1997).

É difícil estender essa caracterização a outros domínios, como o verbal e o nominal. Contudo, como verbos e substantivos denotam domínios estruturados em relações parte-todo (mereologias), imaginemos que essa estrutura também seja, para nossos propósitos, escalar. Formalmente, alguns pesquisadores vêm defendendo que a modificação gradual requer domínios estruturados monotonicamente (NAKANISHI, 2007), aproximando esses predicados. Por exemplo, se tenho 5 maçãs, tenho 4 maçãs, e assim por diante; se tenho $1,78 \mathrm{~m}$ de altura, tenho $1,77 \mathrm{~m}$ de altura, e assim por diante.

Feitas essas breves considerações, inicio com uma incursão na gramática da gradação, discutindo alguns problemas que vejo na forma como o fenômeno vem sendo discutido nas nossas gramáticas tradicionais e apresentando noções básicas do tratamento do tema pela Semântica Formal.

Na seção seguinte, discuto as locuções graduadoras coloquiais. Um objetivo secundário é mostrar que as expressões em estudo pertencem a esse conjunto, exercem a função semântica em discussão, isto é, operam sobre o grau do predicado. Nesse sentido, adotaremos o critério semântico proposto por Guimarães (2007): um advérbio de intensidade expressa quantidade/intensidade.
Para caracterizar formalmente a operação de intensificação, assumimos Kennedy (1997), que propõe que os modificadores graduais denotam relações entre graus. Assim, a intensificação é uma relação parcial (" $\geq$ ", isto é, 'pelo menos') entre graus. Discuto essa denotação na seção 3. Não poderei fazer uma análise muito profunda dessa hipótese aqui. Como já escrevi um texto para cada conjunto de expressões ${ }^{6}$, escolhi apresentá-las nesse estudo como dois conjuntos com muitas semelhanças justamente para ilustrar a generalidade do fenômeno, cuja compreensão adequada transcende a semântica dos adjetivos graduais, hipótese que gostaríamos de destacar.

\section{0 grau}

A análise gramatical centrada na palavra, herança greco-latina, ainda faz com que discutamos a gradação tomando-a como um fenômeno essencialmente ligado a adjetivos e advérbios. Intuitivamente, a gradação envolve predicados que denotam domínios organizados em diferentes relações (maior/menor, parte-todo etc.). O estudo da modificação gradual, por sua vez, envolve caracterizar formalmente como diferentes modificadores operam sobre esses domínios. Os graus do adjetivo são um exemplo típico da modificação.

Vejamos as orações em (3), encontradas em qualquer gramática escolar. Nas gramáticas contemporâneas, os advérbios de intensidade ou os graus do adjetivo são discutidos muito rapidamente ${ }^{7}$. As sentenças exemplificam os diferentes graus que um adjetivo pode exibir.

${ }^{6}$ Fizemos isso em Souza (2017) para pra burro etc.; e em Souza (no prelo), para "à beça", "às pampas"

7 Neves (2000), Castilho e Ilari (2008) ou Bagno (2011) são exemplares nesse sentido. Como contraste, na gramática de Perini (2016) não há sequer uma seção para discutir construções de modificação adjetival como as orações comparativas, consecutivas ou os advérbios de intensidade como "muito", "pouco" etc. 
(3) a. João é alto.

b. João é mais alto que o Pedro

[positivo $]^{8}$

c. João é o homem mais alto da cidade.

d. João é altíssimo.

e. João é muito alto.

[comparação canônica]

[superlativo relativo]

[superlativo absoluto sintético]

[superlativo absoluto analítico]

Do ponto de vista da semântica referencial ${ }^{9}$, o estudo da gradação, em particular da modificação adjetival, tem que responder: a) qual a denotação de um predicado gradual como "alto"; b) qual a denotação do modificador gradual: a comparação (de superioridade "mais", inferioridade "menos" e igualdade "tão"), dos superlativos (absoluto - "íssimo" e relativo "o ... mais"), do grau positivo e dos advérbios de intensidade "muito", "demais", "bastante", "pouco", "um pouco" entre outras expressões que possam pertencer a essa classe; e c) como essas duas denotações se combinam composicionalmente (KLEIN, 1980; KENNEDY, 1997).

Do ponto de vista da abordagem gradual, um adjetivo gradual não é tratado como uma relação entre um indivíduo e um valor de verdade, uma função de tipo $<e, t>$, pois eles não são intersectivos (KAMP, 1975; PARTEE, 1995; HEIM; KRATZER, 1998; OLIVEIRA, 2001; entre outros). Um predicado dessa classe não denota algo do tipo $A L T O(j)$, em prosa: "João pertence ao conjunto dos indivíduos que são altos".

Uma diferença crucial entre adjetivos não graduais, estes funções $<e, t>$, e os graduais é o fato de que aqueles são intersectivos, enquanto os segundos não. Comparemos os adjetivos vermelho e grande, como ilustração.

(4) a. Este vestido é vermelho.

b. $\mathrm{x}$ é um vestido e $\mathrm{x}$ é vermelho.

${ }^{8}$ A Nomenclatura Gramatical Brasileira não lista o positivo. Considerando gramáticas tradicionais, Bechara (2009) o menciona, mas Cunha e Cintra (2008) não.

9 Trabalhos clássicos são Klein (1980); von Stechow (1984); Kennedy (1997); Kennedy e McNally (2005); Morzycki (2016) e referências lá citadas. Esses trabalhos também tomam a modificação adjetival como o caso básico.
(5) a. Este elefante é grande.

b. x é um elefante e x é grande.

(4a) permite que façamos a inferência em (4b), enquanto (5a) não permite inferirmos (5b). Note que não é possível que (4a) seja verdadeira, enquanto (4b) seja falsa, ou vice-versa. Se o que estou apontando é um vestido vermelho, se segue que esse objeto é um vestido e que é vermelho. Já (5) é diferente. Podemos imaginar uma situação que torne (5a) verdadeira e (5b) falsa. Suponha que (5a) tenha como classe de comparação outros elefantes e que a classe para (5b) seja a classe dos monstros: \{King Kong, Godzilla, Balrog, Elefante\}. Em relação a esse conjunto, o elefante é um indivíduo pequeno, tornando (5b) falsa.

Voltando aos exemplos do início da seção, precisamos de algumas informações adicionais para decidir se (3a) é verdadeira. Podemos assumir que ela é verdadeira se e somente se "João é alto em relação àqueles que são considerados altos no contexto de proferimento", ou seja, o contexto torna a interpretação de alto relativa a uma classe de comparação e seu padrão. Note que a parte da paráfrase "em relação àqueles que são considerados altos no contexto de proferimento" não está expressa linguisticamente, o contexto precisa suprir isso. Além da dependência contextual, Kamp (1975) adiciona dois aspectos importantes. 0 primeiro é que adjetivos graduais tendem a ser vagos e a gerar lacunas extensionais, i.e., há situações em que é difícil decidir se "x é alto" é verdadeira ou falsa. E o segundo é que uma teoria semântica que queira ser composicionalmente adequada deve dar a mesma semântica para esses adjetivos tanto no uso positivo quanto no uso modificado.

Por isso, abordagens tradicionais ${ }^{10}$ têm considerado que existe um operador não pronunciado pos (de "positivo"), que denota uma função

${ }^{10}$ As abordagens tradicionais assumem graus na ontologia, entidades de tipo $\langle d\rangle$. Abordagens alternativas, como a de Kamp (1975), Klein (1980) e Burnett (2014), não assumem graus para lida com as propriedades semânticas dos adjetivos graduais, portanto, a ontologia destes é mais enxuta. 
que buscar no contexto o valor padrão para se ser considerado "alto". Ele é definido como a relação "maior ou igual" entre o padrão contextual, e o grau que o sujeito exibe da propriedade que o predicado denota: [[pos A]]= $A(x, d) \geq d_{\text {padrão }}$ Assim, ele requer que o predicado denote uma relação entre indivíduos e graus. Isso captura formalmente também que "alto" envolve um conjunto de indivíduos organizados ao longo da escala de altura do mais baixo para o mais alto: $\operatorname{ALTURA}_{\text {alto }}(x, d)=\{a>b>c>\ldots>z\}$; e baixo seria o oposto.

Discutamos agora o exemplo seguinte. A expressão do grau comparativo é extremamente complexa e diversa linguisticamente ${ }^{11}$. (3b) pode ser parafraseada nos seguintes termos: "João possui um grau de altura que é maior do que o grau de altura que Pedro possui". Veja que usamos o termo "grau" na paráfrase, justamente porque estamos assumindo que, como dissemos acima, um predicado gradual denota uma relação entre um grau e um indivíduo, formalmente, PREDICADO $(x, d)$, uma função de tipo $<d,<e t>>12$, i.e., uma função de indivíduo a graus na escala codificada pelo adjetivo.

(3a) pode ser parafraseada como "João possui um grau de altura que é pelo menos o grau de altura padrão no contexto de proferimento". Logo, essa abordagem consegue dar uma mesma denotação para o adjetivo nos dois usos, o positivo e o comparativo, embora tenha que assumir que exista um operador fonologicamente nulo responsável por transformar o adjetivo de um predicado de graus em um predicado de indivíduos, em uma função $<e, t>$.

${ }^{11}$ Ver Klein (1991) e Beck (2011) para apresentações dos problemas semânticos, sintáticos e questões

envolvendo a diversidade da expressão do grau nas línguas humanas.
${ }^{12}$ Essa abordagem vem desde Cresswell (1976) e von Stechow (1984). Kennedy (1997) implementa a ideia de maneira diferente, pois trata adjetivos graduais como funções de tipo <ed $>$, como funções de medida, nos seus termos, como funções de indivíduos a graus em uma escala. Para ele, alto denota a função $\operatorname{ALTURA}_{\text {alto }}(x)$.
O superlativo relativo é também uma comparação, talvez por isso usa o mesmo item lexical, "mais", mas possui outra estrutura sintática. Em (3c) a altura de João é comparada não com um indivíduo em particular, mas com um conjunto maior de indivíduos, todos os indivíduos da cidade. Veja que poderíamos converter (3c) em uma estrutura de comparação: "João é mais alto do que todos os homens da cidade". Para Marques (2004), a diferença entre a comparação canônica e a oração superlativa relativa reside na função discursiva. Enquanto a comparação envolve uma estrutura de predicação, a superlativa tem função identificacional, pois o predicado nominal é uma descrição definida [x é $o \mathrm{~N}$ mais A]. Note que o "N mais A" não denota um predicado, mas um indivíduo e o verbo de ligação denota identidade.

Por sua vez, curiosamente, o superlativo absoluto sintético é tratado como sinônimo do absoluto analítico pelas gramáticas. Se isso não é dito explicitamente, essa parece a intenção dos gramáticos ao usar o mesmo termo para se referir às estruturas em que a única diferença é a expressão lexical ou morfológica da modificação. Claramente não é este o caso, pois (6), abaixo, não é uma contradição, o que seria esperado se as expressões fossem sinônimas. Contudo, Bechara (2009) afirma que a diferença é de ênfase. Além disso, a escolha do termo "absoluto" pelos gramáticos revela a intuição de que essa expressão de grau desconsidera a comparação com outros indivíduos no contexto. Para Cunha e Cintra (2008) ele expressa que sujeito possui "alto grau" de uma determinada qualidade.

(6) João é muito alto, mas não é altíssimo.

Comparando o absoluto analítico com o absoluto sintético, note que a significação é distinta. (3e) é verdadeira se "o grau de altura de João é maior do que algum padrão fixado contextualmente considerando aqueles indivíduos que são altos" (KENNEDY; MCNALLY, 2005). Nesse sentido 
"muito" é parecido com o operador "pos" (relaciona o grau dado pela sentença com um grau dado pelo contexto), mas o que conta como "muito" é relativo (varia contextualmente), além de ele ser um modificador vago (gera lacuna extensional), envolver uma avaliação subjetiva do falante, e possuir como domínio de atuação um domínio mais restrito: consideramos apenas aqueles indivíduos que são altos na situação. Esclarecendo, assume-se que a classe de comparação do adjetivo "alto" envolveria indivíduos altos, baixos e aqueles que estão na lacuna extensional; já a classe de comparação de "muito alto" envolveria apenas os indivíduos que são altos e os muitos altos (KLEIN, 1980). Como o absoluto sintético não possui uma caracterização formal na literatura (até onde sei) o que poderia denotar o morfema "íssimo" (e seus morfes)? Digamos, por simplicidade, que seja algo similar a "muito" (é uma relação parcial, considerando um padrão alçado), mas excluindo a comparação com outros indivíduos.

As comparações de igualdade são tratadas em paralelo. (7a) exemplifica a comparação de igualdade canônica, cuja paráfrase pode ser: "o grau de altura de João é maior ou igual ao grau de altura do seu pai". Mas veja que as outras estratégias de construção de comparação de igualdade se prestam a outra espécie de tarefa semântica e gramatical. Elas não comparam o quanto um indivíduo exibe da propriedade em relação a outro indivíduo.

(7) a. O João é tão alto quanto o pai.

b. O João é tão alto quanto é inteligente.

c. O João é alto que nem o pai.

d. O João é alto como o pai.

e. 0 João é alto como uma vara de bambu.

(7b) parece declarar que João apresenta as duas propriedades, pois acarreta tanto que João é alto quanto que João é inteligente. Assim, essa sentença envolve coordenação no plano semântico e não subordinação. Note que "ser alto e ser inteligente" são predicados que não podem ser medidos pela mesma escala. Esse fenômeno é chamado de incomensurabilidade ${ }^{13}$. Como contraste, (8) é semanticamente anômala na leitura canônica da comparação. Ela poderia ser interpretável na chamada leitura metalinguística, em que (8) seria parafraseada por: "é mais apropriado dizer que João é alto do que é apropriado dizer que ele é competente"14.

(8) \#João é mais alto do que competente.

Já (7c) e (7d) poderiam ser vistas como sinônimas de (7a). Contudo, se o predicado for verbal, temos uma leitura de modo.

(9) a. O João correu tanto quanto o pai.

b. O João correu que nem o pai.

c. O João correu como o pai.

Em (9a) estamos comparando dimensões como quantidades de eventos de corrida ou o tempo que o João e seu pai gastaram em um evento único de correr. Mas além dessas leituras, (9b-c) possuem uma leitura de modo que (9a) não possui. Mais concretamente, digamos que (9b) seja parafraseável por "O modo como João correu é o mesmo modo do seu pai". Suponha que o João corra com passadas curtas e essa é a mesma forma de trote de seu pai. O fato importante é que qualquer que seja a paráfrase adequada para essa leitura de modo, (9a) não a apresenta, nos mostrando que "tão quanto", "que nem" e "como" não são plenamente sinônimas.

Além dessas acima, há estruturas que as gramáticas listam dentro das estruturas comparativas adverbiais, mas que Marques (2004) classifica como

${ }^{13}$ Cf. KLEIN (1991) e KENNEDY $(1997 ; 2001)$

${ }^{14}$ Cf. SOUZA. PIRES DE OUVEIRA, 2008; e estudos lá citados. 
'oração relativa de modo', que para ele sintaticamente são coordenadas ${ }^{15}$, não tendo a estrutura canônica da comparação equativa, como em (10a), que seria uma estrutura de subordinação. Os exemplos (10b) e (10c) são de Cunha e Cintra ([2010] 1985, p. 603-604). Semanticamente, Marques vê nessas estruturas uma predição ou restrição adverbial. (10b) é claramente uma comparação de modo, enquanto (10c) é o que tradicionalmente se chama de "símile". Talvez (10c) seja parafraseável por algo como "teus olhos são tão negros quanto as noites de luar são negras", o que daria para essa sentença condições de verdade próxima a estruturas como (10a).

(10) a. João é tão honesto quanto o Carlos.

b. Começaste a correr que nem uma louca.

c. Teus olhos são negros, negros, como as noites sem luar...

Há também construções de modificação de predicados graduais que são tratadas em outros lugares nas gramáticas e não são vistas como envolvendo o mesmo tipo de modificação (MARQUES, 2004). A oração consecutiva (11a) e a proporcional (11b), embora sejam tratadas pela tradição gramatical dentro das orações subordinadas adverbiais, por questões sintáticas, são próximas semanticamente das orações comparativas, pois são também estratégias linguísticas de operação sobre uma propriedade gradual.

(11) a. João é tão honesto que é incapaz de mentir.

b. Quanto mais alunos estiverem inscritos, mais professores serão necessários.

\footnotetext{
${ }^{15}$ Marques (2004) e Diniz (2018) discutem mais profundamente essa questão. Se o critério sintático para caracterização da comparação canônica for a subordinação, muitas estruturas que as gramáticas chamam de comparativas se revelam como coordenadas, principalmente as equativas.
}

Por fim, temos também estratégias de gradação/comparação que não são normalmente apresentadas ou discutidas por gramáticas. Vejamos as sentenças abaixo.

(12) a. Ele está mais perdido que cego em tiroteio.

b. João é honesto, mas tão honesto que nunca colou na escola. c. João é incrivelmente/absurdamente/detestavelmente honesto. d. João é honesto de dar inveja/pena.

e. A fala do homem era triste de cortar coração. (José Lins do Rego, Pedra Bonita $)^{16}$

(12a) é um exagero, embora não seja um caso típico de hipérbole ${ }^{17}$. Um cego em um tiroteio seria uma pessoa bem perdida. 0 grau em que o sujeito estaria perdido, então, é dito estar acima desse, um grau que culturalmente já supomos alto - a sentença tem que ser verdadeira para a comparação funcionar. (12b) é uma oração consecutiva, mas traz a repetição do predicado e um "mas" que não parece ter leitura de contraste adversativo - provavelmente é um elemento de ênfase. Talvez, o contraste estaria na oposição entre a leitura positiva do adjetivo e a intensificada que vem na sequência. Compare (12b) com sua versão não enfática: "João é tão honesto que nunca colou na escola". (12b) possui as mesmas condições de verdade desta outra versão, embora seja mais assertiva em relação à honestidade de João. Em (12c) temos advérbios em "-mente". Todos são formados a partir de adjetivos com significação de exagero ou com conotação negativa. Um adjetivo com conotação positiva é esquisito nesse uso, cf. \#João é felizmente honesto ${ }^{18}$.

${ }^{16}$ Trecho transcrito de REGO, José Lins do. Pedra Bonita. Rio de Janeiro: José Olympio, 1938.

${ }^{17}$ Uma hipérbole pode ser caracterizada como uma sentença que viola a máxima da qualidade e dispara uma implicatura, e.g., Estou morrendo de fome. A frase é literalmente falsa, mas dispara a implicatura de que o falante está exagerando a sua fome. Cf. GRICE, 1975.

${ }^{18} \mathrm{Cf}$. DOETJES, 2008; e também minha intuição em relação ao português. Esse tipo de modificação é pouco estudado, me parece que em tese qualquer adjetivo com essa conotação poderia ser convertido em advérbio e usado como intensificador de maximização. 
Esse último caso produz algumas questões: a) Há necessidade de alguma compatibilidade entre a conotação do adjetivo e sua função de intensificação ou diminuição do grau do adjetivo? b) De que modo isso se combina com a denotação do predicado gradual? c) Que classe de adjetivos pode exercer essa função?

(12d) envolve uma construção causativa. Construção que está na base da formação de maximizadores como vemos em "linda de matar", "calor de lascar", "feio de doer" etc., cuja interpretação de causa está aparentemente apagada em favor da leitura de "grau extremamente alto". (12e) é um caso da mesma natureza, e similar a (12a), por envolver uma hipérbole, mostrando que essas locuções envolvem uma implicatura, a partir da violação da Máxima de Qualidade.

Resumindo a discussão desses casos, a variedade de estratégias linguísticas de gradação, seja com morfemas (o superlativo), seja com itens lexicais (os advérbios de intensidade típicos como "muito", "demais", "bastante" etc.; os atenuadores como "pouco", "um pouco", "ligeiramente"), com locuções (as expressões que discutiremos na próxima parte deste texto), as construções (a comparação canônica, as comparações de modo, as metafóricas, a oração consecutiva e a proporcional), os advérbios em "-mente" e as outras estratégias vistas, só nos revelam a vitalidade e a diversidade do processo gramatical.

Embora o grau seja tradicionalmente discutido considerando a semântica dos adjetivos e advérbios graduais, é um fenômeno que afeta outras classes de predicados, como os verbais e nominais (SAPIR, 1961; MARQUES, 2004; GUIMARÃES, 2007). Doetjes (2008) se pergunta se haveria algo de especial nos adjetivos para considerarmos esse tipo de modificação um fenômeno essencialmente adjetival. Afinal, graduadores modificarem predicados de outras classes sintáticas, como verbos e substantivos, é algo visto amplamente nas línguas. Por que, então, os exemplos em (3) são o caso básico? Acredito que uma resposta está na visão anglocêntrica de formulação de teorias: very, por exemplo, é um modificador essencialmente adjetival; e a análise da comparação nos textos clássicos (CRESSWELL, 1976; VON STECHOW, 1984; KENNEDY, 1997; BECK, 2011) analisa a comparação adjetival e marginalmente considera estruturas comparativas com substantivos ou verbos.

Ilustrando esse questionamento, vemos que a comparação pode tomar como alvo um predicado de várias classes lexicais (SOUZA, 2010): em (13a) "mais" modifica o advérbio "rápido"; em (13b) o verbo gradual "gostar"; em (13c) o predicado modificado por "mais" é o verbo "estudar" e temos duas leituras, em uma se compara a quantidade de eventos de estudar e na outra, o tempo que durou o evento (ou eventos) de estudo; em (13d) se compara a quantidade de bananas com a quantidade de laranjas.

(13) a. O João comeu mais rápido que o Pedro. b. 0 João gostou mais do livro que do filme. c. O João estudou mais do que todos os outros alunos. d. O João comprou mais bananas do que laranjas.

Os advérbios graduadores exibem a mesma liberdade composicional (ou sintática) que a comparação canônica. Guimarães (2007) mostra que "muito, pouco, demais, bastante", intensificadores típicos para ele, modificam classes de predicados que denotam propriedades graduais, como adjetivos e advérbios, e alguns outros predicados de estado verbais, além de verbos que denotam conjuntos de eventos e substantivos - e também funcionam como pronomes (e.g., Muitos não gostam disso.) e núcleo de predicados nominais (e.g., Isso é muito pra mim.). Mas enquanto no domínio gradual o advérbio modifica o grau exibido pelo indivíduo no contexto, no domínio dos eventos e dos substantivos o advérbio modifica a quantidade. 
Para o autor não é coincidência que usemos a mesma expressão para as duas operações: quantificar sobre indivíduos e operar sobre o grau de uma propriedade indicaria que a gramática subjacente a essas duas operações deve ser a mesma. Nas palavras dele, "[...] a intensificação, entendida como um tipo de quantificação sobre o grau das predicações, é um tipo de quantificação" (GUIMARÃES, 2007, p. 78).

Não discutiremos essa proposta com maior profundidade. Como comentei, o estudo dessas expressões dentro apenas do âmbito da modificação de adjetivos e advérbios impediu que se considerasse que a mesma modificação também afetava verbos e substantivos. Assim, é sintomático que no domínio nominal "muito" fosse tratado pelas nossas gramáticas como um pronome indefinido, pois é um termo cujo valor é buscado no contexto, (e.g., Muitos não acreditam nisso / O menino comeu muito).

Passemos agora à discussão dos dois grupos de graduadores coloquiais.

\section{Os graduadores coloquiais ${ }^{19}$}

Como dito anteriormente, não aprofundarei a discussão sobre a denotação das expressões. Talvez porque "muito" seja tão amplamente usado e não tenha traços conotativos, novas estratégias surgem para marcar os aspectos que normalmente marcamos linguisticamente via conotação: a ofensa, a coloquialidade/informalidade etc. Uma tese alternativa seria supor que as expressões não denotam o que "muito" denota, afinal não vemos nosso léxico povoado por sinônimos. Contudo, para os propósitos do presente artigo, assumirei que as expressões em estudo são sinônimos

\footnotetext{
${ }^{19}$ Nota terminológica: Guimarães (2007), seguindo a tradição gramatical, chama os advérbios de grau de 'intensificadores'. Já Castilho e Ilari (2008) preferem o termo 'graduadores', entendendo que na classe os 'as expressos', que "graduan para mais", muito, demis, bastante esses sin os 'lntensificadores, e sobre a classificação dos graduadores.
}

cognitivos/de conteúdo (CRUSE, 1986) de "muito" e que as diferenças que possam ser sentidas são somente de registro ou expressivas.

Minha descrição será intuitiva. Interessa-me, neste texto, essas expressões que possuem em comum o traço conotativo de serem extremamente coloquiais e estruturalmente encabeçadas pela preposição pra (para com síncope do $a$ da primeira sílaba) e pela preposição $a$. Em comum as duas preposições conceitualizam trajetória no seu uso mais concreto (ILARI et al., 2008). Mas além da intuição, o que nos garante que estamos diante de graduadores?

Guimarães propõe três critérios para identificar graduador: a) expressa quantidade/intensidade em pelo menos uma de suas ocorrências; b) modifica substantivos, verbos, adjetivos, advérbios, numerais e tem uso como predicado nominal e pronome; e c) é um intensificador típico se expressa quantidade/intensidade em todas as ocorrências. Como veremos, as expressões formadas em "pra" cumprem o requisito semântico e sintático e o conjunto encabeçado por a parcialmente o sintático, pois algumas não modificam todas as classes.

Alguns dados foram colhidos em 2017 no Corpus do Português ${ }^{20}$, no corpus histórico (que contém 45 milhões de palavras, compreendendo textos do séc. XIII ao séc. XX), e serão referenciados como lá se encontram com a sigla ao final (CD). Alguns dados são de intuição (quando não houver indicação de fonte) e outros são exemplos coletados por mim em outros lugares (literatura, internet, redes sociais).

\section{- pra caramba e similares ${ }^{21}$}

A preposição "pra" aparece em combinação com uma expressão que significa quantidade demasiada, exagero, ou um palavrão. Partindo de

${ }^{20}$ Disponível em: www.corpusdoportugues.org. Acesso em: 22 maio 2019.

${ }^{21}$ Nos dicionários, como o Houaiss, se registradas, essas locuções são definidas como significando "grande quantidade" ou "intensidade". Além disso, elas são classificadas como pertencentes a um registro coloquial ou chulo (no caso de pra caralho/cacete ou pra porra). 
alguns estudos na literatura (FULGÊNCIO, 2008; SAITO, 2013) chegamos à seguinte lista de expressões: "pra burro", "pra cachorro", "pra cacete(a)", "pra caralho" (e suas versões atenuadas: "pra caramba", "pra caraca”, "paca”, "pacas", "pacarai” etc.), "pra chuchu”, "pra dedéu”, "pra porra”, "pra danar", "pra foder".

Como temos uma lista razoável, é de se supor que a formação dessas locuções não seja idiossincrática. Embora "dedéu" não tenha uso fora da expressão, o significado dos termos tem relação com "exagero", como é o caso dos termos ofensivos. "Caralho", "burro", "cachorro" são termos chulos, se usados em atos de fala com o objetivo de ofender pessoalmente o interlocutor (e.g., Seu burro!). Já "chuchu" e "dedéu" conotam grande quantidade. Caramba é interjeição de admiração ou surpresa sincronicamente, mas deriva de caralho $^{22}$.

Essas expressões modificam as classes de predicados básicas. (14a) é o uso canônico, modificando o adjetivo. Assumamos hipoteticamente que "pra caralho" expresse que "o grau que o sujeito exibe da propriedade gradual ser vivo é maior do que o padrão contextualmente dado" (voltaremos a esse tema na próxima seção). Em (14b) temos a modificação de um advérbio de modo, também com leitura de intensidade.

(14) a. 0 cara é vivo pra caralho. (Rubem Fonseca, Lúcia McCartney, p. 68)23 b. Ele compõe bem pra caramba. (Kiko Loureiro, CD) ${ }^{24}$

Modificando substantivos e verbos de eventos, elas quantificam sobre a quantidade de indivíduos. Em (15a) temos um sintagma nominal que se

${ }^{22}$ Sérgio Rodrigues (20/02/2017) cita como fonte o dicionário da Real Academia Espanhola. Disponível em: http://abrai/2huMrZa. Acesso em: 22 maio 2019.

${ }^{23}$ Trecho transcrito de FONSECA, Rubem. Lúcia McCartney. Rio de Janeiro: Agir 2009

${ }^{24}$ Os exemplos do Corpus Davies (CD) serão referenciados como lá se encontram. Todos os exemplos que encontrei nesse corpus são de entrevistas ou de gêneros que permitem um uso coloquial, como que encontrei nesse corpus são de entrevistas ou de gêneros que permitem um uso coloquial, como a direto dos personagens. refere a uma grande quantidade de ladrões. (15b) é uma declaração sobre o quanto o sujeito se envolve em eventos de escrita, o que produz muitos textos escritos. Em (15c) temos um verbo estativo, e nesse caso a leitura é de intensidade. Minha hipótese é que a dimensão é esta porque um predicado de estado é como um nome massivo. Embora tenha estrutura interna, essas unidades mínimas não são contáveis - vide a impossibilidade de estativos serem modificados por advérbios de frequência. Assim, a única dimensão disponível é a intensidade. Afinal, embora seja um verbo, não denota um evento, mas uma situação estativa (não dinâmica), como os adjetivos.

(15) a. Você mora numa quebrada violenta, ladrão pra caralho. (Mano Brown, CD) b. Eu tenho muito texto escrito, escrevo pra caramba. (Wagner Borges, CD) c. Eu pensava "puta merda, eu gosto pra caralho desta cidade". (Rubem Fonseca, Lúcia McCartney, p. 84) ${ }^{25}$

Em (16) temos uma leitura que chamarei de "qualidade". (16a) não é uma declaração sobre a quantidade de eventos de jogar, mas sobre o quão bem o indivíduo joga. "Muito" também produz leitura dessa natureza, $\mathrm{cf}$. (16b), exemplo de Guimarães (2007, p. 105).

(16) a. Ele tem que chegar no campo e jogar pra caralho, com arte. (CD) b. Eu não jogava muito, mas jogava todo dia, oito horas por dia.

Se as leituras geradas pela combinação do intensificador com os diferentes predicados parece ser fruto do que o predicado refere, mais especificamente, do tipo de domínio que o predicado denota e como ele se organiza, como é que temos leitura de qualidade com esse tipo de predicado? Note que a relação é sistemática:

${ }^{25}$ Trecho transcrito de FONSECA, Rubem. Lúcia McCartney. Rio de Janeiro: Agir, 2009. 
(17) Classe do predicado

Nomes contáveis

\section{Dimensão}

Quantidade de indivíduos

Nomes massivos

Volume

Predicado verbal plural

Predicado verbal estativo

Adjetivo/Advérbio

Quantidade de eventos/duração do evento Intensidade

Intensidade

Quer dizer, se há indivíduos discretos temos leitura de "grande quantidade" para nomes contáveis plurais e eventos, e "grande duração no tempo", para eventos; se não, temos leitura de volume global (ou outra dimensão) para nomes massivos cf. (18). Para a leitura de qualidade com os verbos de atividade como em (16), por simplicidade, poderíamos assumir que temos um advérbio, "bem", na forma lógica, não pronunciado. Aparentemente, essa leitura só está disponível para verbos que denotam atividades que envolvem alguma habilidade física ${ }^{26}$.

(18) Bebi vinho pra cacete ontem na janta.

\section{- à beça e similares ${ }^{27}$}

Além de "à beça”, temos "às pampas" (variante: “a pampa”), “a rodo, às pencas", "aos montes". Agora, nem todas as expressões desse conjunto modificam todas as classes. Em relação à interpretação, ela é a mesma vista para as locuções com "pra", como veremos.

Todas se combinam com substantivos, como (20c) atesta - não encontramos exemplos com todas as expressões no Corpus Davies. A única estranheza é o uso de "às pencas" nesse contexto.

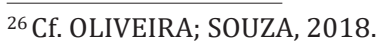

${ }^{27}$ As locuç̃̃es que aparecem no Houaiss são registradas como linguagem coloquial, significando "grande quantidade". Interessantemente, apenas "à beça" e "às pampas" também significam "intensidade". Não vou incluir exemplos aqui de "a dar com um pau".
(20) a. A Noite do Havaí estava cheia. Mulher de sarong e pareô às pampas. (Rubem Fonseca, Lúcia McCartney, p. 69) 28

b.Acredito que o Brasil tá se especializando no ramo somente de pornochanchada - porque: é ganhar dinheiro_a_rodo_somente por safadeza. (CD)

c. $\mathrm{O}$ menino bebeu água à beça/às pampas/a rodo/\#às pencas/aos montes.

Repare que (20c) é ambígua. Em uma leitura a modificação incide sobre um nome massivo e temos leitura de volume. Essa leitura também parece fruto da referência do nome, isto é, um domínio com unidades mínimas não contáveis. Logo, só posso "medir" a referência de um nome massivo pela dimensão do volume. As locuções poderiam tomar como escopo o SV todo, "bebeu água", nesse caso, a leitura é de que temos uma grande quantidade de eventos de beber água. Podemos imaginar que o menino tenha sido agente de muitos eventos de beber água, sem que necessariamente tenha bebido muita água ao final deles. E por outro lado, se o escopo do modificador é o substantivo, também podemos supor que ocorreu apenas um evento de beber e que nesse evento o menino bebeu uma grande quantidade de água. Assim, vemos que as duas leituras descrevem situações distintas no mundo.

Já na modificação de adjetivos (21b), "a rodo", "às pencas" e "aos montes" não podem modificar os adjetivos graduais alto e baixo. Vou supor que isso se deve à concretude do nominal que compõe a expressão. Elas não possuem problema algum em modificar quantidade de objetos, e é bem possível que tenham surgido na língua com essa função, como sugeri em Souza (no prelo). Como a gramaticalização delas não é plena, a concretude do nome impede a modificação. A pesquisa no Corpus Davies trouxe apenas "à beça" e "às pampas" modificando adjetivos, o que corrobora a nossa intuição em (21b).

${ }^{28}$ Trecho transcrito de FONSECA, Rubem. Lúcia McCartney. Rio de Janeiro: Agir, 2009. 
(21) a. Confesso que fiquei triste às pampas, disse o jovem. (Paulo Mendes Campos, $O$ amor acaba, p. 74) ${ }^{29}$

b. 0 menino é alto/baixo à beça/às pampas/\#a rodo/\#às pencas/\#aos montes.

Vemos algo similar com verbos. A pesquisa no corpus revelou poucos exemplos, e para algumas expressões não houve nenhuma ocorrência com verbo (caso de "às pencas", "aos montes" e "às pampas") ${ }^{30}$. À beça e a rodo se combinam com verbos de atividade $(22 a-b)^{31}$. Essa ausência corrobora minha intuição com verbos estativos e processos/atividades (22c-d).

(22) a. Além do mais, Amaury era letrado e um dos poucos habilitados a desempenhar aquele servicinho, que podia parecer porqueira, mas ajudava à beça. (Joyce Cavalcante, Inimigas íntimas, 1993, CD)

b.Após a partida dos hóspedes, Paulo Bento riu a rodo e o negro acompanhante bobeou-se de alegria. (Caio F. Abreu, Onde andará Dulce Veiga?, 1990, CD)

c. O João gosta à beça/às pampas/a rodo/\#às pencas/\#aos montes da Maria.

d. O João correu à beça/às pampas/a rodo/\#às pencas/\#aos montes.

Como aqui a pesquisa em corpus me soa inconclusiva, o ideal seria fazer testes de aceitabilidade, o que fica para trabalhos futuros. Ainda assim, poderíamos interpretar a ausência de exemplos de modificação de verbos com algumas das expressões como evidência para a anomalia semântica das combinações em (22c-d). E podemos atribuir a anomalia também ao estágio de gramaticalização da expressão.

${ }^{29}$ Trecho transcrito de CAMPOS, Paulo Mendes. O amor acaba. São Paulo: Companhia das Letras, 2013. ${ }^{30}$ Talvez isso se deva a uma limitação do corpus, pois "às pampas" é uma expressão muito produtiva, como uma rápida busca no Google mostra.

exemplo de escrita literária também corrobora essa hipótese.
A expressão aos montes exerce somente modificação nominal (23). Intuitivamente, em (23a) "candelabros aos montes" se refere a uma grande quantidade de candelabros. (23b) é a mesma coisa, mas como o termo quantificado é retomado por um pronome, "eles", a locução aparece posposta ao predicado verbal, "chegar na cadeia".

(23) a. Por lá há desses candelabros aos montes. (Rachel de Queiróz, O galo de ouro, 1985, CD)

b. Hoje eles chegam na cadeia aos montes, todos os dias, com 18, 19, 20 anos, e pouco depois estão barbarizando. (Sérgio, 1997, CD)

O contraste entre esses dois casos nos mostra que aos montes, embora seja uma expressão que opere sobre a quantidade de indivíduos, é um modificador verbal, pois não faz parte do SN. Cf. (24) ou (23b):

(24) Por lá há aos montes desses candelabros.

A impossibilidade de essa locução modificar outros domínios, o gradual ou de eventos (25), pode ser atribuída à sua alta concretude. Aos montes não designa abstratamente "grande quantidade", mas seria ainda interpretada literalmente como "um monte de objetos". Em (23a) e (23b) é essa a leitura. Logo, estaríamos frente a um uso hiperbólico que dispara uma implicatura de qualidade, levando o ouvinte a interpretar a expressão como "grande quantidade de objetos", sem que necessariamente formem um monte.

(25) a. \#João é honesto aos montes.

b. \#João correu aos montes.

\section{Síntese}

Vimos que as locuções com "pra" não fazem restrição sintática, podendo se combinar com todas as principais categorias lexicais de predicados. Das 
encabeçadas por "a", algumas, caso de "aos montes" e "às pencas", não se combinam com verbos e adjetivos. Enquanto a rodo está em um uso que parece esporádico.

O uso como pronome e como predicado nominal, usos que "muito" possui, não são possíveis com as locuções em estudo.

(26) a. Os alunos não foram bem na prova. Muitos/*pra caramba/*a rodo tiraram nota baixa.

b. Contexto: Alguém colocou uma quantidade de ração além do normal no pote de comida do cachorro. Falante A: - Isso é muito/*pra caramba/*a rodo.

Guimarães toma "muito" como o típico intensificador e como baliza para o estudo das outras expressões. "Muito" é um item lexical extremamente produtivo. Isso indica que pode ter, com o tempo, assumido funções que seus pares de classe não possuem. Portanto, digamos que essas funções sejam marginais, e quem nem todos os termos dessa classe precisem exercê-las. A função semântica dos intensificadores é modificar predicados graduais, então, ser ele mesmo um predicado ou ter uma função pronominal são funções secundárias.

Resumindo, alguns fatos podem ser elencados desta análise:

a) no domínio nominal a escala é sempre de quantidade com nomes contáveis e volume com nomes massivos;

b) com verbos tivemos leitura de intensidade com estados, quantidade de eventos, ou tempo com verbos que denotam eventos, e ainda uma leitura de qualidade com verbos de atividade.

Essas diferentes leituras já tinham sido constatadas em outros estudos descritivos para "muito" e outros modificadores graduais (GUIMARÃES, 2007; MARQUES, 2004; OLIVEIRA; SOUZA, 2018; GOMES, 2018). Minha sugestão é que a escala de medição é uma propriedade referencial, depende de como o domínio é organizado. Mas isso precisaria ser explorado com mais detalhe, como dissemos acima.

Não mostramos ao longo da discussão, mas uma restrição típica dos graduadores é sua agramaticalidade com predicados singulares, no caso de predicados verbais (27a) ou nominais (27b), e com predicados adjetivais não graduais. Essas restrições também se aplicam às locuções em estudo, como os exemplos abaixo atestam.

(27) a. \#A bomba explodiu pra caramba/às pampas.

b. \#Tinha uma mulher pra caramba/às pampas na festa.

c. \#O passarinho está morto pra caramba/às pampas.

\section{Breve análise sobre a semântica das locuções}

Retomando, do ponto de vista referencial, o estudo das expressões graduais precisa responder, pelo menos, as seguintes perguntas: a) qual a denotação de um predicado gradual?; b) qual a denotação do operador gradual?; e c) como essas duas denotações se combinam composicionalmente?; Vamos sugerir algumas respostas para as duas últimas questões nesta seção.

Vimos que o papel sintático que a expressão ocupa na oração é o mesmo de "muito", modificando adjetivos, advérbios, verbos e nomes, e que as interpretações são as mesmas: intensidade e grande quantidade. Embora, em termos de ordem, apareça tipicamente posposto ao predicado que modifica.

No Quadro 1 vemos os nomes e seus respectivos significados concretos. Podemos nos perguntar o que há em comum nesse conjunto aparentemente diverso. O significado das locuções tem sido descrito pelos dicionários como "quantidade/intensidade". Suponhamos que o que as une é uma ideia de "excesso", ou a relação de superioridade entre dois valores. Não 
é óbvio, me parece, mas vou assumir, por simplicidade, que o caráter ofensivo dos palavrões "caralho", "cacete" e "porra" possa ser conceituado como conotação, pois me parece um traço expressivo do significado dessas palavras.

Quadro 1 - Do conjunto com pra

\begin{tabular}{|l|l|l|}
\hline Expressão & Denotação & Conotação \\
\hline Pra caralho/cacete & Pênis & Ofensa/palavrão \\
\hline Pra porra & Sêmen & Ofensa/palavrão \\
\hline Paca(s)/Pra caramba & Eufemismo de pra caralho & \\
\hline Pra chuchu & Vegetal & Coisa sem graça \\
\hline Pra cachorro/burro & Animal & Ofensa \\
\hline Pra dedéu & $?$ & $?$ \\
\hline
\end{tabular}

Fonte: Elaborado pelo autor.

Comparemos com as locuções em "a". Agora o nominal conota grande quantidade. "Beça", como "dedéu", não possui livre ocorrência fora da expressão. Deixei lacunas no Quadro 2 porque não temos uma conotação clara para a expressão "às pampas" como temos nos casos anteriores. "A rodo" e "aos montes" talvez sejam a exceção nesse conjunto.

Quadro 2 - Do conjunto com $a$

\begin{tabular}{|l|l|l|}
\hline Expressão & Denotação & Conotação \\
\hline À beça & $?$ & $?$ \\
\hline Às pampas & Campo & $?$ \\
\hline A rodo & Instrumento de limpeza & $?$ (Grande quantidade) \\
\hline Aos montes & Pilha de coisas & Grande quantidade \\
\hline
\end{tabular}

Fonte: Elaborado pelo autor.

Apesar das diferenças, o resultado é sistemático. Uma palavra ofensiva (ou com conotação negativa) ou uma palavra que designa grande quantidade de objetos perde sua concretude e denota apenas "grande quantidade/ intensidade", ou "excesso".

Sobre a contribuição da preposição, nossa proposta é que o significado relacional da preposição ainda está lá, com alteração na natureza dos seus argumentos: o que antes era um lugar concreto no espaço, agora é um lugar abstrato em uma escala. Assim, teríamos o seguinte esquema:

$$
\begin{aligned}
& \text { (28) a. João foi para casa. } \quad \text { PARA(IR, casa) } \\
& \text { b. João comeu pra caramba. PRA(coisas comidas, caramba) }
\end{aligned}
$$

No seu uso como complemento circunstancial de lugar para relaciona um verbo de movimento e o ponto final da trajetória, a meta, esquematizado conceitualmente em (28a). Se nossa analogia procede, enquanto o primeiro argumento em (28a) é um evento, em (28b) passa a ser um conjunto de indivíduos. 0 segundo argumento é essencialmente o mesmo, o nominal continua referindo um lugar: agora a relação é entre um conjunto de objetos e uma posição na escala, $\operatorname{PARA}(\mathrm{X}, \mathrm{d})$, ou uma escala de quantidade/ intensidade.

Mas veja que, como os outros intensificadores, esse valor (a posição na escala), onde está o $d$ é relativo ao contexto de proferimento, o ponto na escala em que esse grau é posto e o padrão com que é comparado, negociado discursivamente.

Formalmente, sugerimos que o significado da expressão seja (29):

(29) $\left[[\right.$ pra/a X] $]=\lambda P . \lambda x . \exists d\left[P(x) \&\right.$ PARA $\left./ A(x, d) \& d>d^{\prime}{ }_{\text {padrão }}\right]$

Em essência, a locução modifica predicados com algum tipo de estrutura interna (o que poderia ser codificado lexicalmente como um pressuposto), produzindo um predicado de indivíduos, que denota o grau (quantidade, intensidade etc.) de indivíduos dentro daquele domínio $\mathrm{P}$ e o valor desse 
grau é relativo a outro grau d' dado pelo contexto. Os nomes, "caramba", "cacete", "chuchu”, "pampas", "beça” etc. seriam os nomes desse grau. E isso poderia estar desencadeando a reanálise dessa locução como "muito".

Esse grau contextual é o que Neeleman, de Koot e Doetjes (2004) chamam de 'âncora'32. Uma característica das expressões que os autores chamam de 'expressões graduais avaliativas' é ter seu grau determinado por um ponto de comparação suprido contextualmente ${ }^{33}$.

Essa contribuição contextual poderia ser feita de maneira explícita, através de uma' 'classe de comparação'. Em (30a) o sintagma preposicionado "para um menino de 10 anos denota um subconjunto relevante para a avaliação da verdade da proposição "João é muito alto". Não avaliamos a altura de João em relação a todos os humanos, mas em relação à altura dos meninos de 10 anos. Assim, desse conjunto é que se tira o grau de referência padrão e se afirma que há uma diferença entre essa altura e a de João. Veja que as locuções em discussão também podem ocorrer com esse tipo de classe de comparação.

(30) a. João é muito alto para um menino de 10 anos.

b. João é alto pra cacete/à beça para um menino de 10 anos.

As análises da literatura seguem a tendência das gramáticas tradicionais ao tomar a gradação como um fenômeno essencialmente adjetival, e, como consequência, definem a semântica dos operadores graduais como um tipo de modificador que tem como argumento um predicado de tipo $<$ d,et $>$ ou parecido. Neeleman, de Koot e Doetjes (2004) fazem o mesmo. Talvez isso funcione para o inglês e outras línguas germânicas que possuem advérbios

\footnotetext{
${ }^{32}$ Kennedy e McNally (1999) chamam de 'valor padrão'.

maração os dois pontos da escala são supridos e o papel da expressão comparativa é designar que há uma diferença entre eles.
}

que fazem restrição de categoria e modifiquem só adjetivos e advérbios graduais. Mas para o português esse não é o caso. Por isso a natureza tipológica do argumento que a locução pede é deixada não especificada na entrada lexical em (29).

Podemos seguir Marques (2004) ou Guimarães (2007), e assumir que, para os efeitos da modificação gradual, o que importa é que a propriedade seja escalar, ou como eu prefiro, que tenha algum tipo de estrutura interna não singular (contável ou massiva, no caso dos nominais e eventos; ou gradual, no caso de adjetivos/advérbios). No caso da teoria proposta por Neeleman, de Koot e Doetjes (2004), a entrada lexical proposta para um modificador como very. "muito", não pode ser transposta para outras classes de predicados sem modificação, justamente porque ela assume que a propriedade fundamental do predicado é ser do tipo que adjetivos graduais são. Claro, essa é uma restrição semântica necessária, para evitar que modificadores dessa natureza se combinam com adjetivos não graduais. Tratar essa restrição como um pressuposto é o caminho mais simples, nos parece. O que importa na modificação é que os adjetivos/advérbios sejam graduais, e os nomes e verbos denotem um predicado com estrutura interna (não singular). Fosse um processo diferente, deveríamos esperar estruturas ou operadores diferentes se manifestando linguisticamente.

Claro, em inglês temos a oposição entre many/much (modificadores nominais) e very (modificador adjetival), mas também temos expressões nessa língua que transitam pelas classes, como a lot, "muito". A diferença entre os termos não implicaria que estamos diante de duas operações gramaticais diferentes, mas que o operador é capaz de visualizar a estrutura interna do predicado, particularmente suas propriedades referenciais.

Apesar desses problemas, não é uma dificuldade insuperável para abordagens como a de Klein (1980) ou Kennedy e McNally (2005) elaborarem algum mecanismo de mudança de tipos que possibilite que 
um modificador gradual se combine com outro tipo de predicado não adjetival.

Concluindo, respondemos duas das perguntas. Sugerimos uma entrada lexical para as expressões e discutimos seu papel composicional. Podemos questionar se a pergunta (a) é fundamental para a compreensão do papel dos graduadores. Nesse ponto as locuções mostraram uma assimetria. Enquanto as locuções encabeçadas com "pra" não mostraram restrições de categoria ${ }^{34}$, as encabeçadas por a mostraram restrições: "a rodo", "às pencas" e "aos montes" só modificam nomes.

\section{Considerações finais}

Vimos, primeiramente, que a gramática da gradação envolve não apenas o estudo dos chamados graus típicos do adjetivo/advérbio, mas também a consideração de estruturas e expressões que não modificam apenas essas classes e não se restringem às operações clássicas de comparação e formação do superlativo.

Como exemplo, analisamos posteriormente as locuções encabeçadas por "pra" e $a$. Os exemplos nos mostram que elas se comportam como graduadores típicos, gerando leitura de intensidade ou quantidade, e uma de qualidade na modificação de predicados verbais que denotam atividades, que pode ser reduzida à de intensidade. As formadas por "pra" não fazem seleção de categoria e obedecem à restrição semântica típica desse tipo de expressão, modificando apenas predicados com estrutura interna ou

${ }^{34}$ Embora sejam mais produtivas com adjetivos: das 18 ocorrências de "pra caralho" no CD, 9 eram modificando adjetivos. Mas com "pra caramba", a segunda locução com mais ocorrências, 14, 5 delas eram com predica od tivais/adverbiais, e o restante com verbos. Já com "pra burro", a terceira com com predicados adjetivais/adverbiais, e o restante con varos. Já com "pra burro", a terceira colocada com 12 ocor. adjetivos e advérbios. Cf. SOUZA, 2017; para um relatório mais detalhado das quantidades de dados
coletados. graduais. No caso das encabeçadas por $a$, as muito concretas "às pencas" e "aos montes" fazem restrição de categoria, só ocorrendo com substantivos, e mesmo assim não são plenamente graduadores no plano sintático, pois não formam constituinte com o substantivo.

Por fim, sugerimos que a locução pode ser analisada composicionalmente - embora tudo indique que ela já é uma expressão fixa (SOUZA, 2017). "Pra” denotaria uma relação entre um indivíduo e uma posição em uma escala. A proposta captura a intuição de que um modificador dessa classe é uma expressão que toma um predicado de indivíduos e cria um predicado de indivíduos. Deixaremos a tarefa de implementar formalmente essa análise com mais detalhes para outro momento.

\section{Referências}

BECHARA, Evanildo. Moderna gramática portuguesa. 37. ed. Rio de Janeiro: Nova Fronteira, 2009.

BECK, Sigrid. Comparison constructions. In: VON HEUSINGER, Klaus; MAIENBORN, Claudia; PORTNER, Paul (ed.). Semantics: an international handbook of natural language meaning. Berlin: De Gruyter Mouton, 2011. v. 2, p. 1341-1389.

CASTILHO, Ataliba Teixeira de; ILARI, Rodolfo. Advérbios predicadores. In: ILARI, Rodolfo; NEVES, Maria Helena de Moura (org.). Gramática do português culto falado no Brasil. Campinas: UNICAMP, 2008. v. 2, p. 413-456.

CRESSWELL, M. J. The semantics of degree. In: PARTEE, Barbara H. (ed.). Montague grammar. New York: Academic Press, 1976. p. 261-292. https://doi.org/10.1016/B9780-12-545850-4.50015-7

CRUSE, D. A. Lexical semantics. Cambridge: Cambridge University Press, 1986.

CUNHA, Celso; CINTRA, Lindley. Nova gramática do português contemporâneo. 5. ed. Rio de Janeiro: Lexikon, 2010. 
DINIZ, Vitor Rodrigo. Construções comparativas no português brasileiro: uma análise sintática. 2018. Dissertação (Mestrado em Linguística) - Programa de Pós-Graduação em Letras, Universidade Federal do Paraná, Curitiba, 2018.

DOETJES, Jenny. Adjectives and degree modification. In: MCNALLY, Louise; KENNEDY, Christopher (ed.). Adjectives and adverbs: syntax, semantics, and discourse. New York: Oxford University Press, 2008. p. 123-155.

FULGÊNCIO, Lúcia. Expressões fixas e idiomatismos do português brasileiro. 2008. Tese (Doutorado em Linguística e Língua Portuguesa) - Programa de Pós-Graduação em Letras, Pontifícia Universidade Católica de Minas Gerais, Belo Horizonte, 2008.

GOMES, Ana Paula Quadros. Restrições aspectuais à distribuição do advérbio baixo muito. Cadernos de Estudos Linguísticos, Campinas, v. 60, n. 1, p. 198-221, jan./abr. 2018. https://doi.org/10.20396/cel.v60i1.8649885

GRICE, H. Paul. Logic and conversation. In: COLE, Peter; MORGAN, Jerry L. (ed.). Syntax and semantics. New York: Academic Press, 1975. v. 3, p. 41-58.

GUIMARÃES, Márcio Renato. Dos intensificadores como quantificadores: os âmbitos de expressão na quantificação no Português do Brasil. 2007. Tese (Doutorado em Estudos Linguísticos) - Programa de Pós-Graduação em Letras, Universidade Federal do Paraná, Curitiba, 2007.

HEIM, Irene; KRATZER, Angelika. Semantics in generative grammar. Oxford: Blackwell, 1998.

ILARI, Rodolfo et al. A preposição. In: ILARI, Rodolfo; NEVES, Maria Helena de Moura (org.). Gramática do português culto falado no Brasil. Campinas: UNICAMP, 2008. v. 2, p. 623-808.

KAMP, Hans. Two theories of adjectives. In: KEENAN, Edward L. (ed.). Formal semantics of natural language. Cambridge: CUP, 1975. p.123-155. https://doi.org/10.1017/ CB09780511897696.011

KENNEDY, Christopher D. Projecting the adjective: the syntax and semantics of gradability and comparison. 1997. Dissertation (Master in Linguistic) - University of California, Santa Cruz, 1997.
KENNEDY, Christopher; MCNALLY, Louise. Scale structure, degree modification, and the semantics of gradable predicates. Language, [s. l.], v. 81, n. 2, p. 345-381, June 2005. https://doi.org/10.1353/lan.2005.0071

KLEIN, Ewan. A semantics for positive and comparative adjectives. Linguistics and Philosophy, [s. l.], v. 4, n. 1, p. 1-45, Mar. 1980. https://doi.org/10.1007/BF00351812

KLEIN, Ewan. Comparatives. In: VON STECHOW, Amim; WUNDERLICH, Dieter (ed.) Semantics: an international handbook of contemporary research. Berlin: Walter de Gruyter, 1991.p.673-691.

MARQUES, Rui. Para uma semântica das construções comparativas em português. 2004. Tese (Doutorado em Linguística) - Universidade de Lisboa, Lisboa, 2004.

MORZYCKI, Marcin. Modification. Cambridge: Cambridge University Press, 2016.

NAKANISHI, Kimiko. Measurement in the nominal and verbal domains. Linguistics and Philosophy, Dordrecht, v. 30, n. 2, p. 235-276, Apr. 2007. https://doi.org/10.1007/ s10988-007-9016-8

NEELEMAN, Ad; VON DE KOOT, Hans; DOETJES, Jenny. Degree expressions. The Linguistic Review, Dordrecht, v. 21, n. 1, p. 1-66, Mar. 2004. https://doi.org/10.1515/ tlir.2004.001

OLIVEIRA, Roberta Pires de. Semântica formal: uma breve introdução. Campinas: Mercado de Letras, 2001.

OLIVERA, Roberta Pires; SOUZA, Luisandro Mendes de. Um rascunho para a semântica de muito: explorando a semânticade delineação. Cadernos de Estudos Linguísticos, Campinas, v. 60, n. 1, p. 222-241, jan./abr. 2018. https://doi.org/10.20396/cel. v60i1.8649812

PARTEE, Barbara H. Lexical semantics and compositionality. In: GLEITMAN, Lila R.; LIBERMAN, Mark (ed.). An invitation to cognitive science. Cambridge: MIT Press, 1995. v. 1, p. 311-360.

SAITO, Fabiano Santos. Algumas expressões idiomáticas hiperbólicas do Português Brasileiro e suas relações com os frames de Avaliação e Massa Quantificada. Gatilho 
Juiz de Fora, v. 8, n. 3, maio 2013. Disponível em: http://www.ufjf.br/revistagatilho/ edicoes-anteriores/ano-viii-numero-16-maio-de-2013/. Acesso em: 18 jun. 2019.

SAPIR, Edward. O grau: um estudo em semântica. In: SAPIR, Edward. Linguística como ciência. Seleção, tradução e notas de J. M. Câmara Jr. Rio de Janeiro: Livraria Acadêmica: 1961. p. 161-203.

SILVA, José Romerito. O grau em perspectiva: uma abordagem centrada no uso. São Paulo: Cortez, 2015.

SOUZA, Luisandro Mendes. Comparativas quantificacionais no português brasileiro: sintaxe e semântica. 2010. Tese (Doutorado em Linguística) - Programa de PósGraduação em Linguística, Universidade Federal de Santa Catarina, Florianópolis, 2010.

SOUZA, Luisandro Mendes. Semântica formal e mudança de significado: o caso dos intensificadores. In: CONGRESSO INTERNACIONAL DA ABRALIN, 10., 2017, Niterói. Anais [...]. Niterói: UFF, 2017. p. 1038-1050.

SOUZA, Luisandro Mendes. Sobre a origem de intensificadores encabeçados por preposições. In: ILARI, Rodolfo; BASSO, R. História do português brasileiro: semântica. São Paulo: Contexto. No prelo.

SOUZA, Luisandro Mendes; OLIVEIRA, Roberta Pires. Aspectos da semântica da comparação metalinguística. In: ENCONTRO DO CELSUL, 8., 2008, Porto Alegre. Anais [...]. Porto Alegre: UFRGS, 2008.

VON STECHOW, Armin. Comparing theories of comparison. Journal of Semantics, [s. l.], v. 3, n. 1-2, p. 1-77, 1984. https://doi.org/10.1093/jos/3.1-2.1 